\title{
Preparing non-traditional students for engineering degrees
}

\author{
N. M. Adams ${ }^{1} \quad$ C. J. Hayes ${ }^{2} \quad$ A. J. Dekkers ${ }^{3}$ \\ J. Pienaar ${ }^{4}$
}

(Received 7 January 2016; revised 30 June 2016)

\begin{abstract}
Engineering employment in Australia is cyclic in nature. Australian Government reports indicate that in the past five years there has been a threefold increase in the average number of candidates for engineering positions and a doubling in the proportion of vacancies filled. Until relatively recently there was a surplus in engineering positions; making engineering an attractive career option for students. Students tend to decide on their study direction based on the present economic climate, thus the present downturn in the resource sector and the reduction of engineering positions may result in another shortage of engineering graduates in five years' time. Previous shortages in qualified engineers, combined with the Australian Government's widening participation
\end{abstract}

http://journal.austms.org.au/ojs/index.php/ANZIAMJ/article/view/10435 gives this article, (c) Austral. Mathematical Soc. 2016. Published August 15, 2016, as part of the Proceedings of the 12th Biennial Engineering Mathematics and Applications Conference. ISSN 1446-8735. (Print two pages per sheet of paper.) Copies of this article must not be made otherwise available on the internet; instead link directly to this URL for this article. 
agenda, have attracted many non-traditional students to pursue engineering degrees. The number of non-traditional students entering the Bachelor of Engineering at Central Queensland University has more than doubled between 2011 and 2014. As engineering bachelor degrees have mathematics prerequisites or assumed knowledge, non-traditional students use enabling programmes to gain entry into these degrees at Central Queensland University. In this study we examine the effectiveness of enabling mathematics units preparing non-traditional students for a bachelor of engineering degree.

\section{Contents}

1 Introduction

2 Context

C127

2.1 STEPS mathematics textbooks . . . . . . . . . .

2.2 Instructional videos . . . . . . . . . . . . . . . . C C130

2.3 Formative assessment and feedback . . . . . . . . . C130

2.4 Self-assessment . . . . . . . . . . . . . . . C131

3 Employment and study

4 Transition from STEPS to engineering

5 Student performance

C135

6 Conclusion

C137

References 


\section{Introduction}

Changes in Government policies and university enrolment practices have made it easier for non-traditional students to return to study. The recent engineering shortages and accompanying high rates of pay made the engineering study path attractive [14], especially to those with trade backgrounds. This article examines the success of non-traditional students entering an engineering undergraduate degree from an enabling programme in the context of an Australian regional university.

\section{Context}

Central Queensland University (CQU) is primarily a regional university with 22 study locations across Australia. Although the University is focused on establishing a multi-location multi-modal identity, the historically perceived main campus is in Rockhampton, Queensland, Australia. CQU caters to approximately 20000 students per year with $61 \%$ of these enrolled in distance education mode [8]. Averaged over the last five years, approximately $56 \%$ of students are over 25 years of age, $58 \%$ are female and $43 \%$ are low socio economic status (LSES). The University offers a Skills for Tertiary Education Preparatory Studies (STEPS) programme to prepare students for undergraduate studies.

The STEPS programme was initiated in 1986 after funding was obtained from a government grant aimed at bridging the gap between tertiary education and under-represented groups of people - including Aboriginal people, migrants, women, people from low socio-economic backgrounds and those from isolated areas [11].

This programme now runs on several CQU campuses and in distance mode. It "has evolved to meet the changing needs of people who have not been able to attain their educational goals through traditional educational path- 
ways" [2]. In 2015 the programme catered to 1915 students, of which $64 \%$ were women, $54 \%$ were over the age of 25 , and $57 \%$ studied by distance education. Since 2012 the number of students has almost doubled and there has been a $12 \%$ increase in the proportion of younger people (25 years of age and below).

The programme offers three levels of mathematics designed to satisfy the recommended and prerequisite mathematics requirements for all CQU undergraduate programs. Enrolment in the units is dependent on the student's desired undergraduate degree. Students wishing to enter engineering degrees are required to have the mathematics equivalent to Queensland Mathematics B (studied in years 11 and 12). "The Senior Syllabus in Mathematics B is a recommended precursor to tertiary studies in subjects with high demand in mathematics, especially in the areas of science, medicine, mining and engineering, information technology, mathematics, finance, and business and economics" [5]. This often requires the students to complete all three STEPS mathematics units, detailed below.

- Fundamental Mathematics for University (FMU) - This unit provides a refresher in the fundamentals of basic mathematics, which are necessary to develop mathematics as a unified body of knowledge. Topics covered in the unit include number types, operations with numbers (including rules of precedence), percentages, introductory algebraic manipulation, introductory statistics, exponents (indices), solving algebraic equations, coordinate geometry of a straight line, and units and their conversions. Students may sit a test to skip this level of mathematics.

- Intermediate Mathematics for University (IMU) - This unit gives students introductory knowledge of various mathematical topics including statistics, probability, absolute values, inequalities, simultaneous equations, quadratic equations, functions, logarithms, trigonometry, geometry, variation, ratio, proportion, financial mathematics, annuities, and series and sequences. Students must pass this unit to enrol in the next level mathematics unit. 
- Technical Mathematics for University (TMU) - This unit is designed to prepare students for undergraduate programs such as engineering. TMU includes additional algebra, matrix algebra, trigonometric ratios, trigonometric functions and their graphs, vectors and oblique triangles, plane analytic geometry, derivatives, applications of the derivative, integration, and applications of the integral. Students who do not pass this unit are not able to enrol into the Bachelor of Engineering.

The unit resource material, located on the learning management system (LMS) contains directions and aides designed to keep students on track with their studies and to provide support. These inbuilt support mechanisms are linked to student activities and examples to promote active engagement. Working through the week's instructions, students are able to read the relevant sections of the textbook; watch instructional videos; complete and check textbook examples; and when they finish a module, formative assessment is completed and submitted for feedback. These components make the units successful and lead to an enjoyable learning experience and increased mathematical confidence [3].

\subsection{STEPS mathematics textbooks}

The textbooks for each of the STEPS mathematics units were specifically written. They were designed so that for each concept there is a concise explanation followed by an example, a real-world application and then, inline with cognitive load theory [25], the student is provided with exercises permitting knowledge to be committed to long-term memory. Explanations are pictorial, not just formulaic. The examples centre on concrete examples which many students have come across in their own life experience. All exercises have fully worked solutions, allowing students to identify errors and correct their mistakes. This encourages self-directed learning and self-assessment. 


\section{$2.2 \quad$ Instructional videos}

The instructional videos were designed to complement the textbooks. The videos were developed using a Tablet PC in conjunction with Camtasia [23]. Using a Tablet PC and recording the screen and voice with Camtasia represents one of the many ways that instructional videos may be created and used [21]. These videos explain the concepts and ideas while allowing the student to view the mental processes involved in problem solving. It is important that students be able to mentally plan a sequence of tactical decisions when forming a strategy for solving equations [22]. The videos enable the student to hear and see the mathematics unfold as if they were in a class situation. Videos are topic specific and only run for approximately seven minutes each, thereby preventing cognitive overload [20]. To avoid passive viewing and engage the students, each video first presents the topic, demonstrates through examples and then provides an activity for the students to attempt. Previous studies indicate that the majority of students watch the supplied videos and find that the videos benefit their learning $[1,3]$.

\subsection{Formative assessment and feedback}

As formative assessment has been found to be the key to student success when studying mathematics [9] and since "teachers need to be aware of what each and every student is thinking and knowing" [16], each module in each of the units has an end-of-module test. This is especially important for distance students, where formative assessment provides the lecturer with an insight into the students' level of understanding so that they are better able to assist them. All tests are submitted through the LMS and marked electronically using a Tablet PC. Using a Tablet PC for marking enables the lecturer/marker to annotate the test and provide prompt quality personalised handwritten feedback. Students are then able to email their responses to the tutor or telephone to discuss any problems, concerns or ideas they may have. 
Feedback provided through formative assessment is not only an important part of the learning process but is also reciprocal. Through the submission of the assessment, the student provides feedback to the lecturer, who in turn provides feedback to the student through marking and annotation. If the student makes a mistake, then the lecturer highlights the mistake and reworks the problem. This allows the student to see where they made their mistake and the correct working. The lecturer is able to monitor an individual student's progress and provide extra assistance if required or monitor the entire class to gain an indication of the general understanding of the mathematical content. Identified weaknesses in the unit content are then able to be addressed.

\subsection{Self-assessment}

Learning and motivation are affected by a student's ability to self-assess [4]. The acquisition of self-assessment skills improves learning and establishes the foundation for lifelong learning [19]. Accurate self-assessment is especially crucial in higher education, although several factors limit the student's ability to accurately self-assess [13]. These factors are:

- information deficits - the lack of knowledge or expertise to accurately assess competence;

- unknown errors of omission - the inability to recognise knowledge gaps;

- information neglect - the failure to take into account information that is at hand.

The units encourage self-assessment habits through the use of fully worked solutions to all textbook exercises and the use of formative assessment. Selfassessment is further supported by the recent introduction of online quizzes with video feedback. 
Table 1: STEPS enrolments and local unemployment.

\begin{tabular}{lrrrr} 
Detail & 2012 & 2013 & 2014 & 2015 \\
\hline STEPS students & 1381 & 1702 & 1822 & 1915 \\
Mackay STEPS students & 87 & 96 & 122 & 141 \\
Mackay unemployment rate & 3.5 & 5.3 & 7.3 & 7.7
\end{tabular}

\section{Employment and study}

STEPS enrolments, especially internal, are linked to regional employment rates. Given that the majority of STEPS students are mature aged, the downturn in the resource sector has resulted in a return to study. Table 1 shows the increase in STEPS student numbers as well as a comparison of enrolments and unemployment rates for the Mackay region [10]. The Mackay campus is used for comparison as it demonstrates the link between regional employment rates and enabling enrolments as this regional town is representative of the effects of resource industry dependence. Metropolitan areas were not as affected and their unemployment rates and enrolments remained relatively steady over the same time period.

Engineering employment in Australia is cyclic with the former shortage of engineers easing over the last few years (Figure 1). This coupled with enrolment trends may cause the number of available positions and the number of suitable candidates to vary significantly. From 2007 to 2012, and coinciding with the mining boom, there was an increase in Mining Engineering degree commencements, including a $74 \%$ increase in the number of completions [17]. This was followed by a 17\% reduction in Mining Engineering degree commencements in 2013 as the boom subsided [17]. The predicted downturn in mining investment over the next two years [15] may further erode the number of commencements. The present downturn in the resource sector and the reduction of engineering positions may result in another shortage of engineering graduates in five years' time due to a lack of students commencing engineering undergraduate degrees $[7,24]$. Even though there are more students returning to study in 
Figure 1: Proportion of engineering professions in shortage in Australia [17].

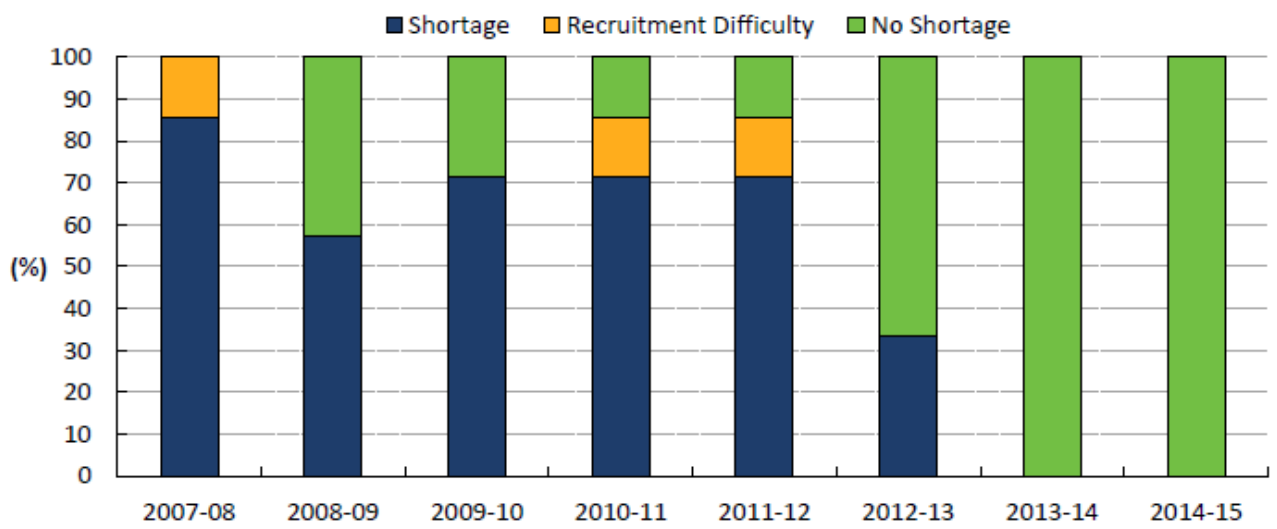

Source: Department of Employment, Skill Shortage Research, assessed occupations only. Occupational coverage varies over the time series.

regional areas, students tend to choose degrees based on current employment demands $[6,12]$. Figure 2 shows the decline in the ratio of STEPS students choosing to enter undergraduate engineering degrees.

\section{Transition from STEPS to engineering}

The TMU unit has small enrolments (Figure 2) as it is only taken by students intending to study engineering, sciences or mathematics education. Although it is offered in all three terms, the majority of students study it in term three. This is mainly due to students working through all three levels of mathematics, and engineering not offering mid-year enrolments. Not all students completing TMU continue to study at CQU, with some discontinuing study and other taking up offers at other universities. Figure 2 shows the number of TMU students who are now studying engineering at CQU. Although the number of students transitioning to engineering remained relatively steady over the period, the proportion reduced from $45 \%$ of the 2012 cohort to $20 \%$ of the 
Figure 2: TMU students transitioning into engineering degrees

120

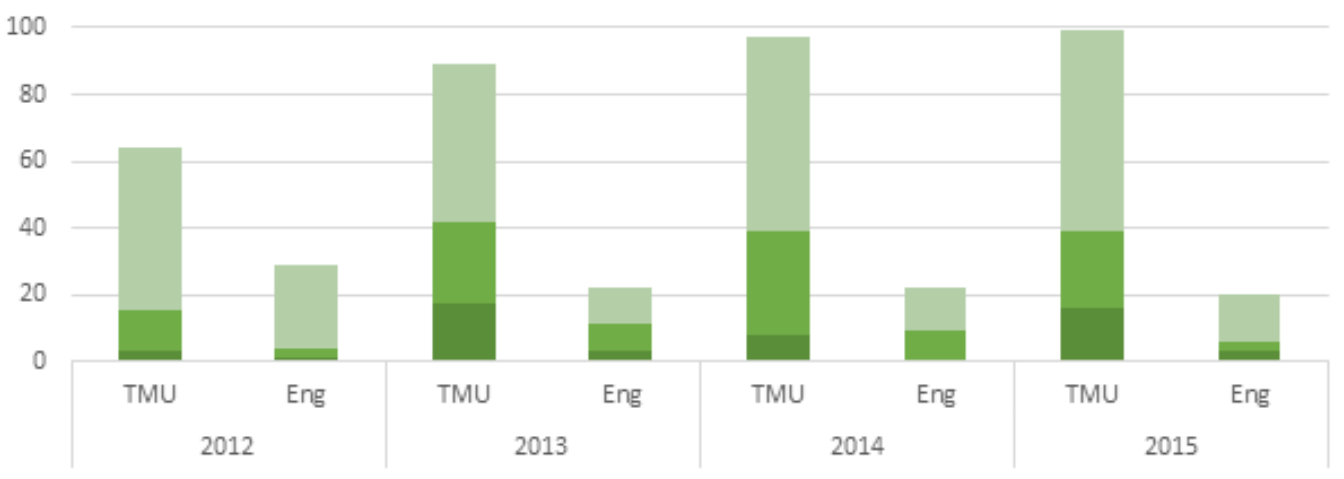

- Term 1 -Term 2 a Term 3

2015 cohort. There are two contributing factors that may be responsible for this drop in transitioning students. The first is a change to the TMU assessment. In 2013 the unit moved from all assignment based assessments to include a supervised examination. Failure to obtain a grade of $50 \%$ for both the assignments and the examination resulted in a failure for the unit. A dramatic drop in pass rates was observed when comparing 2012 to 2013 (67\% down to 44\%). Also, over the four years from 2012 to 2015, as the student numbers increased, the pass rate decreased. The second factor we attribute to the reduction in transitioning students is a reduction in the number of available engineering positions, making this degree less attractive to adult students. The percentages of students that passed TMU in the years 2012, 2013, 2014 and 2015 and chose to study undergraduate engineering were $67.4 \%, 56.4 \%, 55.9 \%$ and $55.6 \%$, respectively. 
Figure 3: Comparison of pass rates for first engineering mathematics subject. $100 \%$

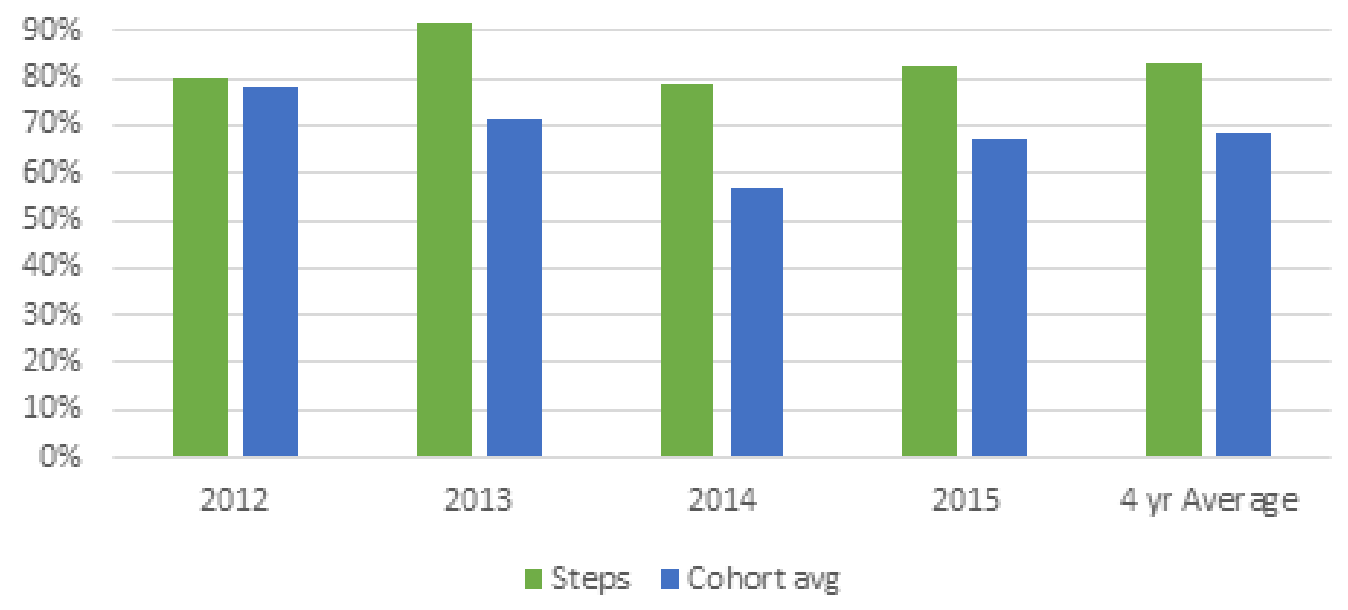

\section{Student performance}

To gain a better understanding of the validity of the STEPS mathematics units in preparing students entering engineering degrees, pass rates were compared for the first level engineering mathematics subject. Using IBM SPSS Statistical Package version $22^{1}$ and calculated at significance level $\alpha=0.05$, a crosstabulation and chi-squared test $\left(\chi^{2}(1, N=579)=4.100\right.$ with probability $p=$ 0.043 indicated a difference in the pass rate of those students who previously passed the STEPS mathematics units and those that had not. When comparing the transitioned students' first level engineering mathematics subject results with those of the entire first year engineering cohort (all students including the STEPS students), it is evident that the STEPS mathematics units provide non-traditional students with the required academic knowledge to achieve better than average results at this level (Figure 3).

Table 2 shows the total number of subjects attempted (some may have been

${ }^{1}$ https: //www-01.ibm. com/support/docview.wss?uid=swg21646821. 


\begin{tabular}{l|rrr|rrr|rrr}
\multicolumn{10}{c}{ Table 2: Transitioned students' achievements. } \\
\begin{tabular}{l|rrrrrrr} 
Year and \\
term in TMU
\end{tabular} & 1 & 2012 & 3 & 1 & 2 & 3 & 1 & 2 & 3 \\
\hline Number of fails & 14 & 4 & 46 & 2 & 5 & 13 & 0 & 10 & 4 \\
Units attempted & 22 & 28 & 285 & 21 & 38 & 98 & 0 & 35 & 56 \\
\% fails & $64 \%$ & $14 \%$ & $16 \%$ & $10 \%$ & $13 \%$ & $13 \%$ & $0 \%$ & $29 \%$ & $7 \%$
\end{tabular}

repeated) and the number of fails for the transitioned students who studied TMU in a given year/term. The 14 fails from 22 attempted subjects (some repeated) is the result of a single student from term 1, 2012. This student did not pass TMU and it is unknown how the student enrolled into engineering. It is difficult to directly compare the STEPS students' later performance against the engineering cohort without manually collecting data on all engineering students individually. Although the STEPS students do appear to continue to perform better than other students (the B.Engineering average failure rate is approximately $29 \%$ ).

The transitioning STEPS students are influenced by more than academic achievement or ability. This finding is supported by May and Chubin [18] who found that academic preparation is only one of the factors leading to success for minority students studying engineering. Table 3 shows transitioned students' withdrawals from the engineering degree. The high withdrawal rate of the 2012 students was on the cusp of the downturn in the resource industry and the change in the demand for engineers. It also coincided with changes to the TMU assessment, which may mean that these students were not as well prepared as students in the following years. The attrition rate of the students in the 2013 and later cohorts is well below the programme average of approximately $32 \%$. It may be that these students are more directed and goal orientated than other students. 


\begin{tabular}{l|rr|rrr|rrrr}
\multicolumn{1}{c}{ Table 3: Transitioned students' withdrawals. } \\
Year and & \multicolumn{3}{c}{2012} & \multicolumn{3}{c|}{2013} & & 2014 & \\
term in TMU & 1 & 2 & 3 & 1 & 2 & 3 & 1 & 2 & 3 \\
\hline Number enrolled & 1 & 3 & 25 & 3 & 8 & 11 & 0 & 9 & 13 \\
Number withdrawn & 0 & 2 & 10 & 0 & 3 & 0 & 0 & 0 & 0 \\
\% withdrawn & $0 \%$ & $67 \%$ & $40 \%$ & $0 \%$ & $12 \%$ & $0 \%$ & $0 \%$ & $0 \%$ & $0 \%$
\end{tabular}

\section{Conclusion}

A downturn in the resource sector and associated increases in the unemployment rates in regional areas has resulted in increases in non-traditional students returning to study. The STEPS programme at CQU offers three levels of mathematics to prepare students for undergraduate study. The mathematics units developed for transitioning engineering students have embedded resources and instructional strategies to support students' developing understanding. Furthermore, the units were developed in accordance with identified student needs. The units provide a range of learning opportunities to accommodate different student learning styles and differing skill levels. The feedback ensures the units are attuned to the student and to the factors impacting upon her/his successful engagement in these mathematics units. We conclude that the mathematics units offered through the STEPS programme adequately prepare students for at least the first level of engineering mathematics.

\section{References}

[1] N. Adams, A. Dekkers, and S. Elliott. Supportive frameworks that increase mathematical knowledge and confidence in students enrolled in bridging mathematics courses. In Proc. Int. Conf. Mathematics, Science and Technology Education, Kruger National Park, South Africa, 2012. 
University of South Africa. http://hdl. cqu .edu.au/10018/928333. C130

[2] N. Adams and C. Hayes. Does teaching with a tablet pc enhance the teaching experience and provide greater flexibility. In Australasian Tablets in Education Conference. Monash University, Dec. 2009. http://hdl.cqu.edu.au/10018/917340. C128

[3] N. M. Adams, C. J. Hayes, S. Elliott, A. J. Dekkers, D. F. Johnston, and R. Dodd. Transformative learning: Increasing the confidence of enabling mathematics students. Int. J. Sci. Math. Tech. Learn. 21(2-3):19-29, 2015. http://ijlsmtl. cgpublisher.com/product/pub.266/prod. 86. C129, C130

[4] J. A. Athanasou and I. Lamprianou. A teacher's guide to assessment. Sense Publishers, 2002.

https://www. sensepublishers.com/catalogs/bookseries/ other-books/a-teachers-guide-to-educational-assessment/ C131

[5] Queensland Study Authority. Mathematics B senior syllabus, 2014. https://www.qcaa.qld.edu.au/downloads/senior/snr_maths_b_ 08_syll.pdf. C128

[6] W. Binney and C. Martin. How do rural students choose their higher education institutions? Two regional Australian cases. J. Institut. Res. Austral. 6:74-80, 1997.

http: //www. aair.org.au/articles/volume-6-no-2/

6-2-how-do-rural-students-choose-their-higher-education-insti $\mathrm{C} 133$

[7] M. Brueckner, A. Durey, R. Mayes, and C. Pforr. The mining boom and Western Australia's changing landscape: Towards sustainability or business as usual? Rural Society, 22(2):111-124, 2013. doi:10.5172/rsj.2013.22.2.111. C132 
[8] Central Queensland University, Australia. Student demographics. CQUniversity Intranet, 2015. C127

[9] G. E. Davis and M. A. McGowen. Formative feedback and mindful teaching of undergraduate mathematics. In Proc. 30th Conf. Int. Group Psychology of Mathematics Education, 241, 2006.

http://www.cees.mak.ac.ug/sites/default/files/ED496931.pdf. C130

[10] Department of Employment. Labour market information portal, 2015. http://lmip.gov.au/default.aspx?LMIP. C132

[11] S. Doyle. STEPS: Celebrating 20 Years 1986-2006. Technical Report, Central Queensland University, 2006. http://hdl.cqu.edu.au/10018/1013477 C127

[12] T. Drewes and C. Michael. How do students choose a university? An analysis of applications to universities in Ontario, Canada. Res. High. Edu., 47(7):781-800, 2006. doi:10.1007/s11162-006-9015-6. C133

[13] D. Dunning, C. Heath, and J. M. Suls. Flawed self-assessment implications for health, education, and the workplace. Psychol. Sci. Pub. Interest, 5(3):69-106, 2004. doi:10.1111/j.1529-1006.2004.00018.x. C131

[14] Engineers Australia. Inquiry into the shortage of engineering and related employment skills. Technical Report, Senate Education Employment and Workplace Relations References Committee, 2012. https://www .engineersaustralia.org.au/sites/default/files/ shado/Representation/Government\%20Submissions/2012/ engineers_australia_submission_to_senate_skills_shortage_ inquiry_-_march_2012.pdf. C127

[15] Australian Government. Budget, 2015.

http://www. budget.gov.au/2015-16/index.htm. C132 
[16] J. Hattie. Visible learning: A synthesis of over 800 meta-analyses relating to achievement. Routledge, 2008. doi:10.4324/9780203887332. C130

[17] Labour Market Research, and Analysis Branch, Department of Employment. Labour market reserch-engineering professions. Technical Report, 2015 https://docs.employment.gov.au/system/ files/doc/other/ausengineeringprofessions.pdf. C132, C133

[18] G. S. May and D. E. Chubin. A retrospective on undergraduate engineering success for underrepresented minority students. J. Engineer. Edu., 92(1):27-39, 2003. doi:10.1002/j.2168-9830.2003.tb00735.x. C136

[19] B. McDonald and D. Boud. The impact of self-assessment on achievement: The effects of self-assessment training on performance in external examinations. Assess. Edu.: Principles, Policy, Practice, 10(2):209-220, 2003. doi:10.1080/0969594032000121289. C131

[20] G. A. Miller. The magical number seven, plus or minus two: Some limits on our capacity for processing information. Psychol. Rev. 101(2):343, 1994. doi:10.1037/0033-295x.101.2.343. C130

[21] A. Porter and S. Denny. Building leadership capacity for development and sharing of mathematics learning resources across disciplines and universities. Technical Report, 2013. http://www.olt.gov.au/ project-building-leadership-capacity-uow-2007. C130

[22] D. Robson, W. Abell, and T. Boustead. Scaffolding for learning equation solving. In Crossing divides. Proc. 32nd Ann. Conf. Mathematics Education Research Group of Australasia. Palmerston North, NZ, 2009. http: //www . merga . net. au/node/38? year=2009. C130

[23] TechSmith Corporation. Camtasia studio version 8.6.0, 2015. https://www.techsmith.com. C130

[24] V. Validakis. Australia entering phase three of mining boom, 75,000 jobs to be cut. Australian Mining, July 2014. 
https://australianmining.com.au/news/

australia-entering-phase-three-of-mining-boom-75000-jobs-to-b C132

[25] J. J. van Merrienboer and J. Sweller. Cognitive load theory and complex learning: Recent developments and future directions. Edu. Psychol. Rev. 17(2):147-177, 2005. doi:10.1007/s10648-005-3951-0. C129

\section{Author addresses}

1. N. M. Adams, Learning and Teaching Services, Central Queensland University, Boundary Road, Mackay, Queensland 4740, Australia. mailto:n.adams@cqu .edu . au

2. C. J. Hayes, Academic Learning Services, Central Queensland University, Bruce Highway, Rockhampton, Queensland 4701, Australia.

3. A. J. Dekkers, Academic Learning Services, Central Queensland University, Bruce Highway, Rockhampton, Queensland 4701, AAustralia.

4. J. Pienaar, Learning and Teaching Services, Central Queensland University, Kent Street, Sydney, NSW 2000, Australia. 